\title{
The influence of pre-commitment and associated player-card technologies on decision making: design, research and implementation issues
}

Sharen Nisbet, Alun Jackson \& Darren R. Christensen

\section{Affiliations}

Sharen Nisbet, PhD, Lecturer, School of Business \& Tourism, Southern Cross University, Gold Coast, Queensland, Australia. Email sharen.nisbet@scu.edu.au

Professor Alun Jackson, Honorary Professorial Fellow, Melbourne Graduate School of Education, University of Melbourne, Carlton, Victoria, 3010, Australia. Email aluncj@unimelb.edu.au

Darren R. Christensen, Assistant Professor, University of Lethbridge, Lethbridge, Alberta, T1K 3M4, Canada. Email Darren.christensen@uleth.ca

\section{Corresponding Author}

Sharen Nisbet, Telephone +61 755893052 Email sharen.nisbet@scu.edu.au

\section{Acknowledgement}

The studies that informed this paper were approved by the University Human Research Ethics Committee (ECN-05-119). No industry funding was provided for this research. 


\title{
The influence of pre-commitment and associated player-card
}

\section{technologies on decision making: design, research and}

\section{implementation issues}

\begin{abstract}
This paper describes player knowledge, attitudes and practices associated with the use of cashless and card based gambling technologies in Australia and considers their influence on player decision making. The experience of gaming venues who have implemented these technologies is similarly considered. Factors that could maximise adoption success and deliver positive outcomes for these venues and their customers are explored.
\end{abstract}

The evidence that unfolded during the two-stage qualitative study of these issues is presented with an emphasis on the implications of the findings for policy makers. Where appropriate, factors that might encourage partial and full use of these systems among players are highlighted. Finally, design, research and implementation issues related to mandatory and voluntary to use cashless and card based gambling schemes are discussed. 


\section{Introduction}

The functionality and likely consequences of the use of cashless and card based gambling technologies (CCBGTs) have been considered and debated by Australian gambling industry stakeholders for more than a decade (Australian Liquor Hospitality \& Miscellaneous Workers Union, 2003; Casey, 2003; Independent Gambling Authority, 2005; Independent Pricing and Regulatory Tribunal, 2004). During this time the industry, ostensibly representing the rights of players, shifted from advocating the widespread introduction of cashless payment technologies, on the basis of their harm minimisation potential (Aristocrat Technologies Australia Pty Limited, 2003; Australasian Gaming Machine Manufacturers Association, 2003; ClubsNSW, 2003), to opposing mandated adoption (Clubs Australia, 2011a, b; Clubs Australia \& the Australian Hotels Association, 2011). Conversely, public policy has shifted from a rejection (Independent Pricing and Regulatory Tribunal, 2004) to acceptance of CCBGTs based on their potential to support player decision making and thus reduce harm (Productivity Commission, 2010).

While there are many possible functions that can be assigned to CCBGTs, the three primary uses in Australian venues include marketing, cashless play and pre-commitment. Most popularly used for marketing, these cards enable players to participate in loyalty schemes that reward player turnover. Venues benefit from this use by gaining a set of rich set of detailed data about the play activity of their customers. Perhaps next most popular is the cashless function which, although not widely adopted and offered by venues is established in several large clubs in both NSW and Queensland (QLD) and in small hotels in Adelaide, South Australia. Despite being an opt-in function required by the relevant legislation, there is 'relatively little interest in pre-commitment' among cashless card adopters (Productivity Commission, 2010, p. C.8).

This pre-commitment component involves EGM players setting limits on their losses before they start to play. While this commitment can be made and met in myriad ways including the popular techniques of budgeting and willpower (McDonnell-Phillips, 2006), the degree to which players 
adhere to non-technological commitments has been questioned on the basis that these commitments are non-binding.

While these alternative EGM payment options are represented on only a small number of machines relative to those that accept cash, they have unarguably changed the nature of the player experience. The dimensions and consequences of that change at the time this study commenced were, however, largely unknown. This paper, then, describes a two-phase study that examined cashless and card-based gambling (CCBG) in New South Wales (NSW), Australia. It focuses on the impact of emerging electronic gaming machine (EGM) payment technologies on two key stakeholder groups, players and gambling organisations.

\section{Change agents, diffusion theory and organisational success}

Changes in gambling behaviour that occur as a consequence of player's use of CCBGTs, and the primary and secondary impacts or consequences of that use on venues were investigated in Study One. The purpose of this study was to understand the role that gaming venue employees play in gambler's new technology adoption. The second was to explore the dimensions of customer use of cashless cards to provide explanations for variations in usage behaviour that could provide some tentative, early theories of player involvement. Thus, a small sample of staff $(n=14)$ from two large venues were interviewed about the process of recruiting and supporting new cashless card users. Each venue that volunteered their staff to this study had around $300 \mathrm{EGMs}$ and 30,000 members, and had introduced the same proprietary card-based gambling system four years earlier.

These employees were asked to describe changes in player behaviour they perceived since the introduction of the system and to reflect on the impact of that introduction on the venue and the players. The development and results of these studies were informed by the technology adoption and use literature. 
Three traditional and connected schools exist for studying technology adoption and use: diffusion, its derivative adoption, and domestication or technological determinism (Wajcman, 2002). Adoption research has developed largely to demonstrate factors or characteristics of the technology that affect its success, using intention or usage as a dependent variable (Venkatesh, Morris, Davis, \& Davis, 2003). While empirically tested and widely applied, many of these models are largely based on projected, rather than actual, use.

Diffusion models encompass elements of adoption research, mapping or predicting technology uptake over a period of time (Rogers, 2003). Diffusion theory is useful in considerations of who might change their behaviour and when, although the extent and consequences of that behaviour change are not often explicated. The diffusion of technologies literature, which often includes observations about the rate and relative success of the adoption of significant public health and environmental initiatives (for example contraception, vaccinations and clean water programs), suggests that key persons, or change agents, are critical in encouraging adoption, training users, and following up to ensure continued and full use of an innovation (Rogers, 2003).

Consistent with the inductive and grounded methodological basis of Study One, a typology of change agent involvement in cashless and card based technology adoption was developed during stage two of this investigation. Evidence from the employees who contributed to this study suggests that they play this change agent role to varying degrees and, consequently, the player adoption outcomes are variable. The results supported the findings of Rogers (2003) to indicate, however, that change agents are critical to ensuring that organisations meet their adoption outcomes.

As the literature was further explored in relation to the emergent findings it was revealed that these staff must be able to: recognise and respond to customer needs; reflect on the effect of customer adoption of cashless mechanisms on their role and responsibilities; and have a deep understanding of the consequences of card use for the venue as well as its customers. This research found that, while most venue employees have highly effective customer service skills, the ability to reflect upon 
and rationalise use in relation to players and the wider organisational and community benefits are higher order communication skills that require venues to invest in staff training and development. The goals of the organisation also need to be clearly stated and, where venues support harm reduction and responsible gambling initiatives, these should be consistent with a goal of good corporate citizenship.

The benefits of such a commitment and investment will be realised by venues as effective and responsive staff who readily observe and respond to the needs of all gamblers. This response could include, but is not limited to, supporting patrons in their decision making around appropriate and effective limit setting, assisting patrons exhibiting problematic usage behaviours to seek help from counsellors, providing exclusion advice and support where appropriate, and reporting unintended and unanticipated consequences of use during trial and evaluation stages.

Employee respondents were also asked to articulate perceived changes in within-session player behaviours that have the potential to affect ongoing use of cashless cards. Of particular interest were those behaviours exhibited by card users that may have a protective function, enhancing decision making and facilitating responsible play. Participants thought that cashless cards allowed players to end a session at a time of their choosing. Removing the card from the machine transfers credits to the player account, which can be collected at the cashier, or retained for play at a later date. Importantly, this allows the player to act on an impulse to end the session without having to wait for a machine attendant. In a study of ticket in - ticket out EGM payment technologies in similarly large venues with ticket redemption machines it was similarly concluded that the ability to quickly end a session had a potentially protective function (Carter, 2006).

The specific functionality of the card also played a role. The ability to 'bank' winnings to the player account and to readily check the balance of that account appeared protective and informational. Incremental transfers of value from the account to the machine were also useful in this way. 


\section{Player knowledge, attitudes and practices associated with their use of}

\section{cashless payment systems}

The second, consecutive study sought to describe player behaviours associated with the use of cashless gambling cards from the perspective of players. In-depth, semi-structured interviews were conducted with 30 Australian cashless player card users $(n=26)$ and non-users $(n=4)$ from two gaming venues in order to explore their experiences.

Gaming employees had a critical role to play in relation to the recruitment of players, recommending participation to those present on the gaming floor at the time the interviews took place. At one venue, the loyalty manager assumed this responsibility while at the other, the duty managers took this on. The player loyalty manager had advised several patrons in the preceding weeks that the research would be taking place, and had sought an initial expression of interest from players that was followed up on the day. At the second venue, players were recruited 'cold' from the gaming floor by various shift supervisors.

These players chose the location of the interview within the venue, which was largely a choice between the lounge/dining area adjacent to the gaming floor or, if reluctant to move away, at the gaming machine. Approximately five players chose the latter option. While this added some complexity due to background noise and privacy, it had the distinct advantage of allowing players to demonstrate behaviours, such as loading and downloading money and checking the card balance, as the interview proceeded. Light (2006) suggests evoking or 'explicating' the experience as a way of encouraging participants to visualise an activity and this was therefore a useful way to increase understanding of the concepts being discussed.

Transcripts of each thirty minute interview were imported into NVivo and analysed using the pragmatic, pattern seeking technique of discourse analysis (Alvesson, 2003; Light, 2006; Potter \& Wetherall, 1987). The philosophy of discourse analysis is to 'show rather than tell' (Light, p. 186). Like most interpretive techniques this can reveal shared and idiosyncratic experiences (Ponterotto, 
2005) which leads to context specific and not readily generalisable results. Nonetheless, the findings were broadly consistent with findings from other subsequent Australian card-based studies.

Confluence is particularly evident in relation to the perceived usefulness of the cashless function of these technologies and low uptake of opt-in responsible gambling features, typically less than one per cent of card users.

The question of whether card users differentially perceive and consequently manage their money was also framed for inclusion in this study. This is relevant to developing understanding of precommitment behaviours generally. Most players asked to reflect on this question said there was no change in the way they perceived their money as a consequence of card use. However, an analysis of the behaviour described during the interviews suggests greater complexity in their attitudes.

The language used by participants provided some initial insight. Many players spoke, for example, of the money on their card as their 'gambling money' or of not having to 'go to your wallet and use your own money'. In this way several players were able to justify assigning most of their winnings to future gambling, and this was facilitated by the cashless account-based function of the card. These cognitions were not, however, exclusive to cashless card players as many participants did differentiate between 'the money we came with' and any winnings, regarding these as money you 'can play with.' For example, 'if it's my own cash I will play some' said one player, adding 'but if its cash that I have won, I will put some back in again.' In the same way, many players also spoke of cash, held in a wallet or purse, as their 'own' money as distinct from money held on the card. There are several examples of this in Chapter Five.

Overall, it appears that play with an account card or tickets assists players to gamble more responsibly as compared to players using cash. Some cashless players won't - or will try not to -play with money in their purse or wallet, and might regularly draw down any winnings from their card and place it there for safe guarding. Cashing out frequently is also a way for many gamblers to keep track of time and money spent (Schellinck, Schrans, Chen, \& Chambers, 2010), and encouraging 
gamblers to keep rather than reinvest their winnings seems a way to encourage the responsible use of EGMs.

Some ticket-using players behave similarly, holding tickets in a pocket or wallet until leaving the gaming floor and using a cashback terminal to convert their tickets to cash at the end of a session. These players perceive cash in a wallet or on a ticket as more inaccessible than the stored value on their card. However, almost as many players indicated that cash in a wallet or purse was there to be spent, regardless of any pre-commitment made prior to entering the venue. Player perceptions of gambling money, then, seem to be shaped by a complex set of values, attitudes and play behaviours that are only partially mediated by its form and designated function.

An alternative explanation for differences in ability to control expenditure by players using different currency substitutes on the gaming floor might also relate to the attractiveness of innovative EGM characteristics to these different player groups. That is, those players most likely to adopt and use cashless cards are, perhaps, more likely to be attracted to more exciting game features such as free spins and faster reel spin speeds. Other studies that have examined the impact of both technological and non-technological limit setting strategies (e.g. willpower, only taking a set amount of cash to the venue) on player behaviour have found a faster rate of play for problem and at risk players (Schellinck et al., 2010; Schottler Consulting, 2011). Encouraging use of card -based responsible gambling features among the existing population of card holders and users seems, therefore, a logical and promising course of action in that it directs efforts at a potentially receptive population of users.

Notably, the users in this study represented a much larger proportion of each venue's gambling turnover, were frequent gamblers, were specifically targeted during the adoption campaigns run at each venue on this basis, had a long association with the venue, and already held and used loyalty cards. This fits the finding of ACNielsen (2007) in their NSW problem gambling prevalence study showing a positive relationship between frequency of play and loyalty card adoption. While players 
in this study said they played with the card inserted in the machine more often than moderate and low risk groups it was also found that problem gamblers had a lower take up of rewards or loyalty cards overall.

This combination of factors means that cashless player accounts are especially attractive to these players described above; many gamblers do not, however, share these characteristics. Further research investigating the barriers to adoption amongst players who are resistant to use is required to ensure that the widest possible number of gamblers will trial then use the system as intended. Adoption campaigns can be designed based these findings.

Such measures aim to reduce the harms of problem gambling by encouraging all players to make rational and conscious decisions about their gambling. Further, it is argued that pre-commitment, particularly where mandatory, could hinder the progression of EGM players from no-risk and at-risk categories to problem gambling status.

Perhaps as a consequence of this voluntariness none of the users of the system investigated in NSW were aware, at the time the study commenced, of the availability of limit and time setting features and they were not used.

When study participants were asked about the likelihood that they would use these features the findings were mixed, with many respondents indicating that it seemed like a good idea or, more wholly, suggesting that as they did not have a problem with their gambling then there was no need for limits to be set around their own gambling behaviour. To a large extent this is consistent with the high level of support shown in various national surveys for pre-commitment that range from 65 to 83 per cent (Creagh, 2011; Essential Media, 2011; Ogilvy Illumination, 2012; Schottler Consulting, 2011). The idea that limits setting and the availability of session information is a good idea for 'other people' seems to be the basis for this level of support. 
While all gamblers are the target of a voluntary, state-wide pre-commitment scheme described in the National Gambling Reform Act 2012 it is likely that the degree of adoption and use will differ amongst groups of players. As the technology adoption scholars Venkatesh, Thong, and Xu (2012, p. 159) have highlighted:

'While in general, voluntariness can be perceived as a continuum from absolutely mandatory to absolutely voluntary, consumers have no organizational mandate and thus, most consumer behaviors are completely voluntary ...'

The intended consequences of adoption for each group of consumers should, therefore, be carefully mapped early in the design, with a view to ensuring that the advantages and disadvantages of use are equitable. For example, there is no evidence to suggest that problem gamblers will be rehabilitated by participation in a state-wide scheme. In all likelihood many of these gamblers will not engage with the responsible gambling features. A further issue, as highlighted by Schull (2012), is that card use advantages venues by allowing the collection and collation of play data that can then be used to entice players into further expenditure. It is possible that many at-risk players are targeted under these schemes.

Conversely, these same at-risk gamblers could benefit from participation by gaining increased awareness of their expenditure and other risky within-session behaviours and appropriately moderate these, perhaps with targeted interventions from staff and referrals to counsellors, although these interventions are not required according to the legislation. Counselling and treatment service providers and gambling venues and their staff are key users of the system. They should be intimately involved in its design and be afforded opportunities to provide feedback throughout the trial and implementation phases. These users will recruit players, encourage full and considered use and, potentially, could intervene where at-risk or problematic play is suspected.

Where a mandatory to use card based system was in place existing self-exclusion schemes could be refined to better deliver benefits to all stakeholders including gamblers and venues. Criticisms of 
many of these programs vary according to how they are operationalised within each jurisdiction but broadly include: deterring participation by gamblers on the basis of privacy concerns; a lack of flexibility in the choice and number of venues from which a gambler can exclude; difficulties for venues and their staff in monitoring and enforcing breaches; and inflexibility regarding the duration of the exclusion period (Hing, Nisbet, \& Nuske, 2009; Peller, LaPlante, \& Shaffer, 2008; Responsible Gambling Council, 2008; Tremblay, Boutin, \& Ladouceur, 2008).

\section{Design, research and implementation issues related to a national cashless and card based} gambling scheme

Legislation passed in 2012 by the Australian Federal Government required that all gaming machines be part of a state-wide pre-commitment system by 2018 , albeit with several exemptions. One of the first provisions of the legislation was for a trial of pre-commitment technology, initially slated for clubs in the ACT (Panichi, 2013). A change of Government in August 2013 has now led to the introduction of legislation to repeal these reforms such that the requirement that venues introduce pre-commitment is unlikely to proceed (Cannae, 2013).

There are, nevertheless, compelling operational reasons for venues to introduce card based technologies although the vagaries of their implementation and adoption will require careful consideration. While the findings of many of the recent studies of CCBGTs are broadly similar, there exist key differences in the EGM environment between jurisdictions that will likely affect the rate and consequences of the diffusion of these technologies. One Australia state's system, for example, has no cashless EGMs and, in that jurisdiction, machines do not accept notes. These venues also have an effective limit of $36 \mathrm{EGMs}$, and are thus much smaller in this regard than the large clubs in other Australian states that permit CCBGTs. These key contextual differences limit the universality of these study's findings even within Australia, and hint at some of the difficulties associated with any proposal to implement and evaluate the effectiveness of, a standard mandatory CCBG scheme across eight Australian jurisdictions. 
Another issue related to system design and implementation stems from an acknowledgement of the marked growth in the availability and use of mobile and contactless payment systems in Australia (International Quality and Productivity Centre, 2012). However, banking system innovations do not necessarily reflect the latest innovation (Merrett, 2012). The implication of this lag is that, despite the failed Federal Government push for a universal card based system the magnetic stripe technology proposed is already out dated and, as acknowledged in several reviews, is not best practice (Parliamentary Joint Select Committee on Gambling Reform, 2011; Productivity Commission, 2010). Gambling consumers are likely to notice this and demand more innovative technologies that match their non-EGM payment experiences.

While a universal Australian CCBG scheme is now unlikely venues will, probably, continue to incrementally adopt these technologies as they look to leverage the resultant play data and player benefits. In addition to its value to venues looking to segment players for loyalty programs this data could be de-identified and made available to researchers. This research could further understanding of the effect of use of these technologies on player behaviour.

Assuming the privacy issues can be appropriately addressed this data could also be used to extend the functionality of the system without adversely impacting the usage experience of the majority of players. For example, harm minimisation messages could be tailored to player segments and delivered dynamically within play. When a player excludes for a period greater than 24 hours, a voucher could be printed with a referral to a counselling service near to the gambler's home in addition to a 24 hour telephone helpline. This simple, tailored intervention could be a way of increasing the number of gamblers seeking help for their behaviour, although close monitoring of the response of gamblers during the trial phase would be required. More controversially, where players are displaying multiple behaviours consistent with problematic or at-risk gambling such as making several withdrawals from ATMs, crying after losing and putting wins back into machines trained venue staff could be permitted to review selected data on the basis of a possible 
intervention (Delfabbro, Borgas, \& King, 2012). This is a technique used by Host Responsibility Coordinators at SkyCity casino in Adelaide, which significantly increases their ability to co-operatively and sensitively manage player interventions (Hing et al., 2009).

Gainsbury (2011) has similarly highlighted the great value inherent in player account data.

Researchers, operators and regulators could all benefit from the prudent and considered analysis of the data that is collected and stored as a consequence of use of cashless card based systems and, as noted earlier, many astute gambling venue operators seeking to maximise the marketing potential of these systems currently do. Although an analysis of this data is not without issue including player consent (despite the ease of de-identification), a key benefit in terms of the effort to improve the efficacy of responsible gambling interventions is an ability to tailor interventions to particular individuals, groups or sub-groups of players. Where behavioural research is being undertaken this can have the advantage of allowing establishment of a control and intervention group from which actual changes in behaviour can be evaluated.

\section{Limitations and future implications}

Limitations related to the method used for each study reported in this paper include the theoretical and purposive sampling methods although, it should be noted, these are sampling strategies consistent with most qualitative and mixed method research approaches (Corbin \& Strauss, 2008; Glesne \& Peshkin, 1992; Silverman, 2005). It is also possible that the timing of each period of data collection, which commenced in the late morning and went through to early evening, was a factor in the high number of female participants.

Similarly, while the interpretive analysis technique used to generate the results is useful in that it can provide a rich and deep understanding of a situation, it is bounded by the time the data for this project was gathered and analysed and the political, social and organisational perceptions of cashless payment technologies. Given the political context of discussions on card-based precommitment systems that existed at the time of these studies there was probably a much greater 
awareness of the issues than there would normally have been; the downside is that public discourse around the issue was narrowly framed.

The link between loyalty programs and cashless card use has not been explored in the research in any detail. These concepts are closely related due to both programs being accessible via the (same) card; and the willingness of participants in this study to frequently discuss their loyalty program participation in lieu of their cashless card use. This was also evidenced by the desire of both managers to have a proposed, but ultimately unsuccessful quantitative analysis include supplementary card-based schemes related to their loyalty/credit card programs.

A further issue likely to impact the future of CCBGTs is the migration of players from land based to online gaming environments. While it is difficult to ascertain how many Australian players supplement or have replaced their venue based gaming with an online experience, the evidence suggests the numbers are increasing (Gainsbury, published online 2015, Apr 11). The NSW Prevalence Survey also found a small but non-significant increase in internet gambling between the 2006 and 2011 surveys from one to two per cent (Ogilvy Illumination, 2012). Competition from online gaming is of concern to the Australian industry and the fact that the now abandoned mandatory card use proposal did not extend to online gambling or betting was cited as evidence of the card use scheme's likely ineffectiveness in reducing problem gambling rates (Clubs Australia, 2011a).

The Scandinavian experience shows that it is possible to design and implement a CCBG scheme that applies to both online and internet gambling (RGC for the Advancement of Best Practices, 2009), while Laplante, Nelson, and Gray (2013) have shown the value of collecting and analysing online play data in order to more accurately pinpoint problematic activity.

\section{Consequences of use}

Consequences of use, while considered in this paper, are difficult to measure because users are not aware of [all of] the effects of adoption (Rogers, 2003). Rogers (2003) suggests that the responses of 
change agents, (in this study the employees of venues and the organisation) will not adequately represent the consequences of use. Nonetheless, it was felt that operations staff may be able to illuminate some the effects of use, and that these observations will be useful in this exploratory context. It was contended that these staff have an affinity with and understanding of gamblers due to the service environment in which they work and play, which differs to that traditional role of the change agent as outsider or government/industry employee.

Consequences are also 'often confounded with other effects' (Rogers, 2003 p.442). There has also been a suggestion that to understand technology use and its consequences requires an untangling of cause and effect - consequences need to be exclusively an outcome of the technology. Being mindful of the original reason for introducing the innovation is paramount to classifying these phenomena (Rogers, 2003).

In NSW the cashless component of the card was introduced by venues to increase profitability through a lowering of overheads associated with cash handling (Nisbet, 2005b) and this research has confirmed that these technologies do indeed achieve this aim. Strong resistance from the gambling industry toward a mandatory card use scheme casts doubt, however, over this finding, suggesting differential costs and benefits related to the implementation of these schemes. It has been noted in the literature that the size of a venue and age of the existing infrastructure are key factors affecting the cost to venues of investing in card- based technologies. The industry also claims that players are resistant to these technologies, wary of the privacy implications and not likely to benefit in any meaningful way from their mandatory use.

Yet, there are many benefits to venues from the adoption of such a scheme, not least the ability to demonstrate good corporate citizenship. The possibility of increasing customer loyalty to a venue as a consequence of introducing these technologies is also very real. 
Each of these claims needs to be carefully assessed not only in the context of the impact on venues of the existing proposal but also with an eye to changes in the form and function of payment technologies that are occurring in the community today, and which will no doubt impact venues in the future.

Future research should consider these issues and also be confirmatory. Ideally, this would involve a comparison of cashless, ticketed and cash-based EGM payment types facilitated by an analysis of gaming machine play data as generated by existing loyalty card users. For this analysis gaming machine play data can be extracted and de-identified. While the sample of players would only comprise those who have signed up to the loyalty program and play the gaming machines with their card inserted, it would nonetheless highlight within session behaviour and answer some of the persistent questions regarding the differential effects of adoption and use of non-cash technologies in gambling venues.

\section{Conclusion}

The possibility that new gambling technologies such as cards might be of assistance in meeting public health goals has only recently begun to be explored. This paper has added to the emergent knowledge around the likely contribution of new technology to changes in gambling behaviour by uniquely examining the adoption and diffusion of cashless and card-based gaming machine payment systems from the organisational and player perspective. While the findings of this exploratory, qualitative work have highlighted the myriad ways in which players perceive and manage their gambling money and the many positive and negative consequences of that use, it is bounded by the research context and method used.

Nonetheless, the findings support some general principals of human behaviour and technology use. Despite the difficulties associated with encouraging players to adopt the card, as evidenced by low rates of adoption, of those who do adopt, the response appears largely positive and it is, therefore, repeated. That is, behaviour is a function of its consequence. This is represented in the use-diffusion 
model proposed in Chapter Six. Understanding actual play behaviour - as explored in the usage part of the model - and intended and unintended consequences of card use is critical, therefore, to ensuring an efficient, universally available scheme: one that is well-designed, has maximum player benefit, and contains the cost to industry while not inhibiting innovation.

Consistent with the findings of other jurisdictions these new technologies are perceived as easy to use and useful. Players contributing to this research did not believe that cashless card use impacted key aspects of their play including individual expenditure, machine choice, session length, or breaks in play relative to their prior non-cashless card use although, somewhat contradictorily, several respondents spoke compellingly about the card's influence on their ability to manage their gambling money. This could be because of the ability to sequester money to the player account, a consequence of the card reader displaying values as dollars rather than credits, or the ability to transfer small amounts to the machine and easily end a session. Each of these aspects appears influential in this respect although further research is required to confirm these effects.

While the technologically based pre-commitment system scheduled for introduction by 2018 appeared to have wide, though conditional, support from a range of gambling industry stakeholders, the impost upon venues and the perceived infringement of personal liberties led to a strong and coordinated anti-precommitment campaign targeting members of parliament sitting in marginal Federal seats. This political discussion distorted the issue, from how to offer technologies that inform and support individual decision making, to how to protect commercial interests from policy decisions that will likely erode profits. Headed by Clubs Australia and supported by the casino industry and Australian Hotels Association, this lobbying effort led to an inability to hold a trial of the technology in the ACT - a key component of the Act - and to the announcement from the current Federal Government to repeal the Act in mid-2014 (Cannae, 2013; Panichi, 2013). 
A well designed, simple user interface and targeted monitoring of the impacts of use in the partial and full implementation phases will ensure that this system meets the needs of many stakeholders. Unfortunately,

Finally, it would be naive to assume that the moderate levels of adoption and use likely to be achieved under this jurisdictionally-based scheme will provide adequate levels of protection to atrisk and problem gamblers. Cashless gaming machine payment technologies have the potential to improve the control players have over their gambling, however additional measures are required to ensure that the benefits are use are appropriately distributed.

It has also been noted that the benefits of voluntary use are marginal compared to other universal responsible gambling measures such as limitations on the maximum bet size and jackpot restrictions (Blaszczynski \& Gainsbury, 2011; Nisbet, 2005a). It has also been submitted that '... only a full mandatory system ... would have the capacity to impose genuine controls on people's expenditure ...' (Delfabbro, 2011, p. 10). Consequently, a whole of system approach should be pursued with gambling counselling and treatment providers co-opted at the design and implementation stages. Venue staff should be appropriately trained in the use of pre-commitment technologies, encouraged to report unintended and unanticipated use, and empowered, via participation in well-designed training programs, to continue to interact with gamblers and respond to suspected problematic gambling behaviours in appropriate ways. 


\section{References}

ACNielsen. (2007). Prevalence of Gambling and Problem Gambling in NSW - A Community Survey 2006. In NSW Office of Liquor Gaming and Racing and Department of the Arts Sport and Recreation (Ed.). Sydney: NSW Government.

Alvesson, M. (2003). Beyond Neopositivists, Romantics, and Localists: A Reflexive Approach to Interviews in Organizational Research. The Academy of Management Review, 28(1), 13-33. Aristocrat Technologies Australia Pty Limited. (2003). Review Of Gambling Harm Minimisation Measures: Pre-Commitment Or Smart Cards That Enable Limits To Be Set (pp. 20). Sydney. Australasian Gaming Machine Manufacturers Association. (2003). Review Of Gambling Harm Minimisation Measures By The Independent Pricing And Regulatory Tribunal Of New South Wales (pp. 129). Crows Nest.

Australian Liquor Hospitality \& Miscellaneous Workers Union. (2003). Submission to IPART.

Blaszczynski, A., \& Gainsbury, S. (2011). Submission to the Joint Select Committee on Gambling Reform Inquiry into Precommitments Scheme. Retrieved from Inquiry into pre-commitments scheme website:

https://senate.aph.gov.au/submissions/comittees/viewdocument.aspx?id=e7eb9a88-abfc4886-83c8-e89b62eadf80

Cannae, S. (2013). Government wants to dump pokie restrictions. Lateline. Retrieved from Lateline website: http://www.abc.net.au/lateline/content/2013/s3906145.htm

Carter, C. (2006). Ticket In Ticket Out Trial and the Impact on Problem Gamblers. Office of Liquor, Gaming and Racing, NSW Government. Sydney.

Casey, A. (2003, 25 July 2003). High tech pokies put thousands of jobs at risk in casinos and pubs. Retrieved 15 August, 2003, from www.lhmu.org.au/lhmu/news/1059085874 16739.html 
Clubs Australia. (2011a). Janelle, why won't you stand up for our community? Lane Cove, Sydney: IMMIJ Printing.

Clubs Australia. (2011b). Parliamentary Joint Select Committee on Gambling Reform Inquiry into PreCommitments Scheme. Clubs Australia Submission. Retrieved from Parliament of Australia Joint Committee website:

https://senate.aph.gov.au/submissions/comittees/viewdocument.aspx?id=8c989a3d-5dd44e26-8053-0190b451915f

Clubs Australia \& the Australian Hotels Association. (2011). It's Un-Australian. Retrieved 3 Feb, 2012, from www.its-unaustralian.com.au

ClubsNSW. (2003). Submission to the Independent Pricing and Regulatory Tribunal of New South Wales (pp. 54): ClubsNSW.

Corbin, J., \& Strauss, A. (2008). Basics of Qualitative Research: Techniques and Procedures for Developing Grounded Theory (3rd ed.). Thousand Oaks, California: Sage Publications.

Creagh, S. (2011, 20 Jan 2013). Almost 75\% suppport gambling pre-commitment rules: Poll. The Conversation. from http://theconversation.edu.au/almost-75-support-gambling-precommitment-rules-poll-2559

Delfabbro, P. (2011). Submission to the Joint Select Committee on Gambling Reform. Submissions Received by the Committee, (No. 2). https://senate.aph.gov.au/submissions/comittees/viewdocument.aspx?id=6d951651-3b174ab0-a463-1e0bd876b038

Delfabbro, P., Borgas, M., \& King, D. (2012). Venue staff knowledge of their patrons' gambling and problem gambling. Journal of Gambling Studies, 28(2), 155-169.

Essential Media. (2011, 20 Jan 2013). Mandatory Pre-commitment Trial. Essential Report. from http://www.essentialmedia.com.au/?s=pre-commitment

Gainsbury, S. (2011). Player account-based gambling: Potentials for behaviour-based research methodologies. International Gambling Studies, 11(2), 153-171. 
Gainsbury, S. (published online 2015, Apr 11). Online gambling addiction: The relationship between internet gambling and disordered gambling. Current Addiction Reports. doi: 10.1007/s40429015-0057-8

Glesne, C., \& Peshkin, A. (1992). Becoming Qualitative Researchers: An Introduction. New York: Longman.

Hing, N., Nisbet, S.L., \& Nuske, E. (2009). Assisting Problem Gamblers in South Australian Gambling Venues. Lismore: Centre for Gambling Education \& Research, Southern Cross University. Independent Gambling Authority. (2005). Inquiry into Smartcard Technology. Adelaide: The Government of South Australia.

Independent Pricing and Regulatory Tribunal. (2004). Gambling: Promoting a Culture of Responsibility. Sydney: Independent Pricing and Regulatory Tribunal.

International Quality and Productivity Centre. (2012). Driving Innovation and Collaboration in the Mobile Payments Ecosystem. Retrieved 20 March, 2013, from http://www.paymentsaustralia.com.au/Event.aspx?id=773950

Laplante, D.A., Nelson, S.E., \& Gray, H.M. (2013). Breadth and depth involvement: Understanding Internet gambling involvement and its relationship to gambling problems. Psychology of Addictive Behaviors. doi:10.1037/a0033810

Light, A. (2006). Adding method to meaning: a technique for exploring peoples' experience with technology. Behaviour and Information Technology, 25(2), 175-188.

McDonnell-Phillips. (2006). Analysis of Gambler Pre-Commitment Behaviour: Gambling Research Australia - Dept of Justice.

Merrett, R. (2012). Banks slow with payment tech innovation. Computerworld. 14 June. Retrieved 26 March, 2013, from http://www.computerworld.com.au/article/427625/banks slow payment tech innovation mhits ceo/ 
Nisbet, S.L. (2005a). Alternative gaming machine payment methods in Australia: Current knowledge and future implications. International Gambling Studies, 5(2), 229-252.

Nisbet, S.L. (2005b). Responsible gambling features of card based technologies. International Journal of Mental Health and Addiction, 3(2), 54-63.

Ogilvy Illumination. (2012). Prevalence of Gambling and Problem Gambling in New South Wales. Sydney.

Panichi, J. (2013). The lobby group that got much more bang for its buck. Inside Story. Retrieved from Inside Story website: http://inside.org.au/the-lobby-group-that-got-much-more-bangfor-its-buck/

Parliamentary Joint Select Committee on Gambling Reform. (2011). The Design and Implementation of a Mandatory Pre-commitment System for Electronic Gaming Machines. Canberra: Commonwealth of Australia.

Peller, A., LaPlante, D., \& Shaffer, H. (2008). Parameters for Safer Gambling Behavior: Examining the Empirical Research. Journal of Gambling Studies, 24(4), 519-534.

Ponterotto, J.G. (2005). Qualitative research in counseling psychology: A primer on research paradigms and philosophy of science. Journal of Counseling Psychology, 52(2), 126-136.

Potter, J., \& Wetherall, M. (1987). Discourse and Social Psychology: Beyond attitudes and behaviour. London: SAGE.

Productivity Commission. (2010). Gambling Report. Canberra: AGPS.

Responsible Gambling Council. (2008). From Enforcement to Assistance: Evolving Best Practices in Self Exclusion. Toronto: Responsible Gambling Council.

RGC for the Advancement of Best Practices. (2009). Play Information and Management System. Toronto, Ontario: Responsible Gambling Council.

Rogers, E.M. (2003). Diffusion of Innovations (5th ed.). New York: The Free Press.

Schellinck, T., Schrans, T., Chen, C., \& Chambers, E. (2010). Evaluating the Impact of the "My-Play" System in Nova Scotia. Halifax, Nova Scotia: Focal Research Consultants. 
Schottler Consulting. (2011). Factors that Influence Gambler Adherence to Pre-commitment.

Brisbane: Gambling Research Australia - Dept of Justice.

Silverman, D. (2005). Doing Qualitative Research. Thousand Oaks, California: Sage Publications.

Tremblay, N., Boutin, C., \& Ladouceur, R. (2008). Improved Self-exclusion program: Preliminary results. Journal of Gambling Studies, 24(4), 505-518.

Venkatesh, V., Morris, M.G., Davis, G.B., \& Davis, F.D. (2003). User acceptance of information technology: toward a unified view. MIS Quarterly, 27(3), 425-478.

Venkatesh, V., Thong, J.Y.L., \& Xu, X. (2012). Consumer acceptance and use of information technology: Extending the unified theory of acceptance and use of technology. MIS Quarterly, 36(1), 157.

Wajcman, J. (2002). Addressing Technological Change: The Challenge to Social Theory. Current Sociology, 50(3), 347-363. doi: 10.1177/0011392102050003004 


\section{University Library}

\section{- M I N E R VA}

\section{A gateway to Melbourne's research publications}

Minerva Access is the Institutional Repository of The University of Melbourne

\section{Author/s:}

Nisbet, S;Jackson, A;Christensen, DR

Title:

The Influence of Pre-Commitment and Associated Player-Card Technologies on Decision Making: Design, Research and Implementation Issues

\section{Date:}

2016-06-01

\section{Citation:}

Nisbet, S., Jackson, A. \& Christensen, D. R. (2016). The Influence of Pre-Commitment and Associated Player-Card Technologies on Decision Making: Design, Research and Implementation Issues. INTERNATIONAL JOURNAL OF MENTAL HEALTH AND ADDICTION, 14 (3), pp.228-240. https://doi.org/10.1007/s11469-015-9574-X.

Persistent Link:

http://hdl.handle.net/11343/282621 